\title{
INVESTIGACIONES
}

\section{ANALISIS DE LA CONVERSACION. UNA PROPUESTA PARA EL ESTUDIO DE LA INTERACCION DIDACTICA EN SALA DE CLASE}

\author{
Conversation analysis. A proposal for didactical interaction \\ research in the classroom
}

Marco Antonio Villalta Páuca

\author{
Universidad de Santiago de Chile, Escuela de Psicología, \\ Av. Ecuador 3650, Estación Central, Santiago, Chile. \\ villalta@tie.cl,mvillalta@usach.cl
}

\section{Resumen}

El artículo ofrece una metodología de análisis de la conversación aplicado al estudio de la interacción didáctica en sala de clase. La propuesta metodológica articula los aportes de la etnografía de la comunicación, la lingüística interaccional y la pragmática de la comunicación en el estudio de la relación profesor-alumnos.

La metodología de análisis de la conversación aquí desarrollada es caracterizada por procesos secuenciales e interrelacionados de fases y secuencias temáticas, intercambios verbales, intervenciones y actos de habla, que configuran la estructura de significados que distinguen un contexto educativo determinado. Ofrece elementos para comprender las prácticas pedagógicas del docente y sus posibilidades de innovación.

Palabras clave: práctica pedagógica, interacción didáctica, análisis de la conversación, intercambio, acto de habla.

\begin{abstract}
The article offers a conversation analysis methodology applied to the research of didactical interaction in the classroom. The methodological proposal articulates the contributions of the communication ethnography, the interactional linguistic and the pragmatic of communication, in the study of the teacherstudent's relationship.

The conversation analysis methodology here developed, is characterized by sequential processes and interrelated stages and thematic sequences, verbal exchange, interventions and speech acts that form the meaning structure that distinguishes a specific educative context. It offers elements to understand the teaching practices and its possibilities of innovation.
\end{abstract}

Key words: teaching practice, didactical interaction, conversation analysis, exchange, speech actions. 


\section{REFERENTES TEORICOS}

Hay un amplio consenso entre los científicos sociales del siglo XX sobre el papel de la interacción del sujeto con el entorno en la generación de la realidad subjetiva e intersubjetiva. Esta, la interacción, se ha convertido en el foco de la investigación social para explicar la acción humana (Ray 2003; Noya 1999; Gregorio 2007; Pérez 2007).

En esta perspectiva, la acción humana es la dimensión tangible de los códigos culturales con que el sujeto interpreta, estructura y transforma la realidad que construye con otros, donde el lenguaje es eje del mundo generado (Bernstein 1990a, 1990b; Halliday 1994; Echeverría 2006).

Con la noción de juego del lenguaje desarrollado, el filósofo austriaco L. Wittgenstein ubica al lenguaje más allá de su papel descriptor de mundo para entenderlo como generador de mundo (Ray 2003). El lenguaje es acción que constituye al sujeto. En la misma dirección apunta la noción de acto de habla, desarrollada por los filósofos ingleses Austin y Searle, que profundiza en el carácter pragmático, interaccional e intencional del lenguaje (Echeverría 2006; Tusón, Calsamiglia 2004; Abril, Lozano y Peña 2004).

Por su parte, la psicología desde sus inicios encuentra en el lenguaje verbal una vía privilegiada para estudiar los aspectos subjetivos que explican la acción humana. Así, por ejemplo, Bajtin y Vigotsky -precursores del enfoque sociocultural en lingüística y psicología soviética de inicios del siglo $\mathrm{XX}$ - estudian al lenguaje como construcción interactiva de apropiación y transformación del entorno social. La subjetividad para Vigotsky será la síntesis histórica del proceso de apropiación a través del lenguaje, de las relaciones sociales en las cuales habita el sujeto (González 2003; Pasmanik y Cerón 2005; Vigotsky 1977).

El psicoanálisis, especialmente la vertiente lacaniana, llega a considerar que el inconsciente tiene la estructura del lenguaje, el cual se construye en relación con otro (Lacan 1966 en Blanco y Bueno 1989). Desde la psiquiatría norteamericana el abordaje del carácter pragmático del lenguaje es inscrito en una compresión amplia de la comunicación entendida como sistema de distintos niveles de complejidad y relación (Watzlawick, Paul; Beavin Bavelas, Janet; Jackson, Don D. 1993; Winkin 1994).

Por otra parte, el vínculo entre lenguaje y realidad social como forma de explicar la acción humana es estudiado por disciplinas como la sociolingüística y sus diversas variantes desarrolladas desde las corrientes microsociológicas de mediados del siglo XX. Es el caso de, por ejemplo, la etnografía de la comunicación desarrollada por Gumperz y Hymes en la década de 1970, que instalan la noción de competencia comunicativa, para dar cuenta del valor contextual del habla. Por su parte, la etnometodología, desarrollada a fines de la década de 1960, estudia las racionalidades prácticas de las acciones discursivas que operan en la vida cotidiana para construir roles e identidad social (Garfinkel 1967; Bonal 1998).

En este amplio y apretado marco de referencia queda en evidencia que sujeto, subjetividad y realidad social se han convertido en términos vinculantes de diversas disciplinas que encuentran en el lenguaje la unidad de análisis para explorar el significado y sentido de toda acción humana.

El lenguaje distingue y vincula, existe y se transforma en relación directa con su poder comunicativo, es decir, la capacidad de promover comunidad, de relacionar personas que cooperan para construir la realidad social. El lenguaje existe de modo vital y cotidiano en la conversación. 
La conversación. Una perspectiva de análisis. Se puede decir que la conversación es la acción cooperativa a través de la cual los miembros de un colectivo reducen la incertidumbre, coordinan las acciones que aseguran la convivencia, consolidando identidad y pertenencia. En tal sentido, el análisis de la conversación pretende dar cuenta de un proceso secuencial e interrelacionado de condiciones comunicativas, secuencias temáticas, intercambios verbales, intervenciones y actos de habla, que enmarcan y constituyen las posibilidades de significado y sentido de los interlocutores en un contexto específico.

Desde la década de los años 1970 se han desarrollado modelos jerárquicos de análisis del discurso dialogal (Sinclair y Coulthard 1975; Mehan 1978; Vion 1992; Kerbrat 1998), para estudiar la estructura de interacción de la relación profesor-alumnos en contexto de sala de clase.

Un autor que profundiza en aspectos componentes de la conversación en una perspectiva jerárquica es Eddy Roulet, de la escuela de Ginebra, quien desarrolla un modelo de análisis a través de conceptos como intercambio, intervención y acto de habla (Roulet, Eddy; Auchlin, Antoine; Moeschler, Jacques; Rubattel, Christian; Schelling, Marianne 1991). En esta misma línea de pensamiento, Kerbrat-Orecchioni (1998) propone un modelo de cinco rangos, a la vez que equipara la terminología de modelos similares desarrollados por otros autores.

Asumiendo el carácter interaccional de toda construcción lingüística, Kerbrat-Orecchioni (1998) distingue entre unidades dialogales, estructuras de lenguaje en que participan al menos dos interlocutores, y unidades monologales, aquellas estructuras dialogales que dependen de un solo locutor. Esto se presenta en la figura 1:

\section{Figura 1}

Estructura jerárquica de la conversación

\begin{tabular}{|l|l|}
\hline \multirow{2}{*}{ UNIDADES DIALOGALES } & $\begin{array}{l}\text { Interacción (o "incursión”). } \\
\text { Secuencia ("transacción", "episodio", "fase", "sección"). } \\
\text { Intercambio ("cambio interno"). }\end{array}$ \\
\hline UNIDADES MONOLOGALES & $\begin{array}{l}\text { Intervención ("movimiento" de Sinclair y Coulthard y de } \\
\text { Goffman, "contribución" de Hudelot). } \\
\text { Actos de habla. }\end{array}$ \\
\hline
\end{tabular}

Fuente: Kerbrat-Orecchioni, Catherine 1998: 213.

En el presente texto se describe una propuesta de análisis de la conversación que recoge los aportes de la lingüística interaccional de la escuela de Ginebra, la sociolingüística y la etnografía de la comunicación. Es evidente que el análisis de la conversación verbal cubre sólo un aspecto de las diversas y complejas interacciones que configuran la comunicación humana. La conversación es, sin embargo, la expresión cultural más elaborada y estable en la constitución de significado y sentido de la acción social y de la identidad de las personas.

En términos operativos, el análisis sigue un proceso que va desde el nivel más general -definición del cuadro comunicativo- hasta el nivel específico de carácter gramatical 
de la conversación -los actos de habla-. Cabe insistir sin embargo, como suele suceder en los métodos cualitativos, que este es un proceso recursivo, interdependiente entre los niveles.

\section{EL CONTEXTO: EL CUADRO COMUNICATIVO}

La conversación necesita y construye un contexto, es decir, un entorno físico o lingüístico para cumplir sus propósitos comunicativos. El contexto está vinculado a roles y dinámicas sociales que caracterizan el tipo de participación en una conversación. El contexto es el Cuadro Comunicativo (figura 2).

El cuadro comunicativo ofrece los elementos para el desarrollo de competencias comunicativas, es decir, formas de participar de modo pertinente en una conversación. Es la referencia sociohistórica que permite comprender el valor y sentido posible que tiene la conversación.

Como se observa en la figura 2, el contexto socioespacial opera como una condición de espacios y tiempos determinados, cuyas funciones y rasgos señalan las posibilidades y límites de la interacción verbal.

Además del contexto socioespacial, hay un contexto extrasituacional (Tusón, Calsamiglia 2004) compuesto por los (a) propósitos y (b) cualidades de los participantes. Los propósitos refieren a los objetivos o motivos que convoca a los interlocutores; estos pueden ser dados (por ejemplo, participar de oyente en una asignatura, pedir consejo psicológico, una entrevista de trabajo, etc.) o construidos (el ejemplo típico es el diálogo espontáneo).

Las cualidades de los participantes en número, estatus de poder social y emocionalidad predisponen una forma de actuación, que moviliza una interpretación del propio rol como interlocutor, que sea coherente a los demás elementos del cuadro comunicativo.

Como se observa en la figura 2, el proceso de participación o cuadro participativo hace referencia a las configuraciones o estructuras de diálogo que establecen los interlocutores en una situación conversacional (Kerbrat-Orecchioni 1998; Vion 1992). Esto es posible en tanto hay cooperación recíproca de los hablantes a través de la coordinación de sus comportamientos verbales y no verbales o kinésicos, que complementan o sustituyen las palabras, enriqueciendo de significados y sentido la comunicación.

El rol de los interlocutores, emisor y receptor, son construcciones dinámicas que no cesan de modificarse en el desarrollo de la interacción. Hay secuencias conversacionales en las que el receptor cumple el rol de emisor y viceversa. Los rasgos del contexto socioespacial condicionan la estabilidad y cambio de estos roles en el tiempo.

Asimismo, en el Proceso de Participación se configuran tipos de receptor, que pueden ser directos o indirectos. El receptor directo es el destinatario del mensaje. Receptor indirecto es aquel o aquellos que participan como espectadores del intercambio, pero son también destinatarios del mismo. No siempre es clara, para un observador externo, la distinción entre receptores directos e indirectos, pero sí lo es para los participantes destinatarios del mensaje, lo que hace posible los diálogos grupales, como, por ejemplo, una clase.

Gestos y palabras configuran estructuras comunicativas que según su mayor o menor estabilidad tipifican roles interaccionales que existen, entre otros factores, gracias a esas 
Figura 2

Cuadro Comunicativo

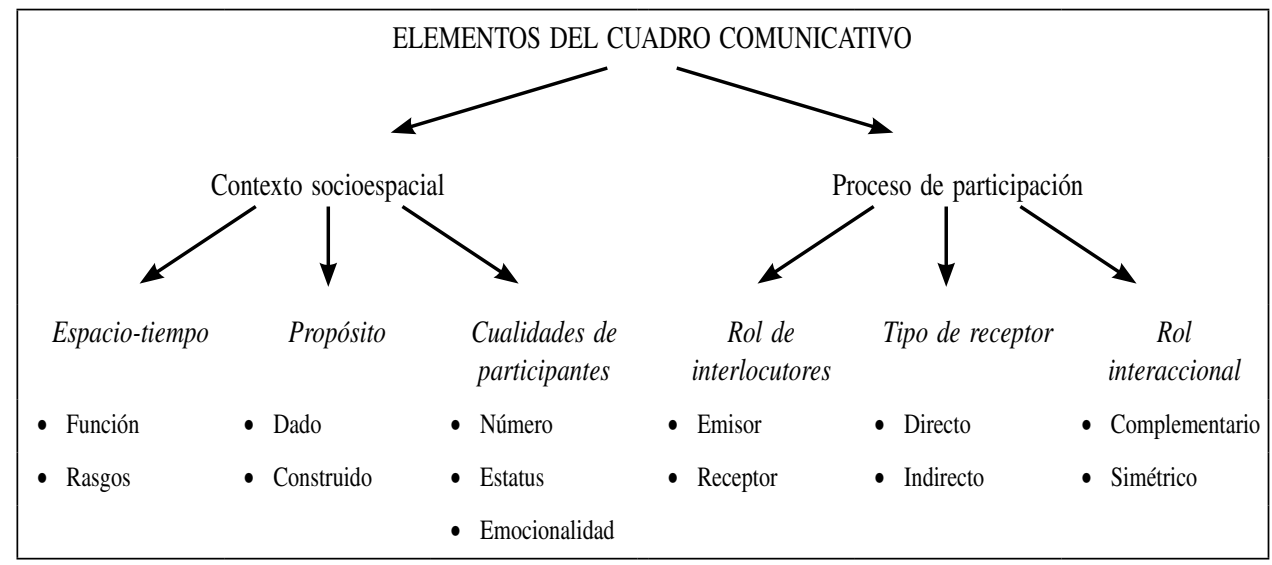

Fuente: Adaptado de Kerbrat-Orecchioni 1998.

prácticas discursivas (Tusón, Calsamiglia 2004). Los tipos de interacción pueden ser, tomando las categorías de Watzlawick (1993), complementarias -cuando hay de por medio roles jerárquicos- o simétricas, cuando ambos roles se asumen sin diferenciación jerárquica, como ocurre en la conversación cotidiana o cuando estas jerarquías se interpretan como equivalentes en un contexto determinado.

Con estos elementos de análisis se puede señalar que el cuadro comunicativo de la interacción didáctica de sala de clase es una construcción espacio-tiempo con propósitos educativos curriculares específicos. En tal sentido, posee una estructura comunicativa donde los roles interaccionales de profesor y alumnos preexisten a los interlocutores.

En tal sentido, comunicarse satisfactoriamente en la sala de clase actuar de modo pertinente al propósito que sostiene los respectivos roles e identidades. La actuación pertinente es un acuerdo tácito y explícito que se confirma cotidianamente entre los interlocutores. Es la cultura de la institución escolar. El logro de dicho acuerdo es el que sostiene una práctica docente y de alumnos determinada.

Sin embargo, no siempre los interlocutores interpretan de la misma manera el contexto, por lo que necesitan redefinir significados cotidianamente en la conversación. Es de considerar entonces que la conversación está condicionada por el contexto y es a la vez transformador del mismo (Kerbrat-Orecchioni 1998; Villalta 2000).

\section{FASES Y SECUENCIAS TEMATICAS. EL PROCESO DE LA CONVERSACION}

La interpretación de los elementos preexistentes a la conversación no se mantiene estable en el tiempo que dura la interacción verbal. Lo común es que el mismo proceso dialogal transforme la situación inicial de la conversación. De hecho, como señalara 
Echeverría (2006), muchas conversaciones tienen como razón de ser transformar las condiciones de su existencia.

Una primera aproximación a la comprensión de la conversación es organizar el periodo observado y registrado en fases y secuencias.

3.1. Fases. Los etnógrafos de la comunicación señalan que en la interacción comunicativa se pueden reconocer tres grandes fases o momentos: (a) Inicio, (b) Desarrollo y (c) cierre. Esta es una primera forma de acercamiento al discurso dialogal (Mehan 1979; Sinclair y Coulthard 1978).

La fase de inicio señala los primeros momentos de la conversación que comúnmente contiene la confirmación recíproca de existencia de los interlocutores y se orienta hacia la construcción de estructuras más complejas de significado. Equivale a secuencias de saludos, preguntas y diálogos que muchas veces son fórmulas rituales pertinentes al contexto.

La fase de desarrollo es el cuerpo central del tiempo de interacción verbal, comúnmente es anunciada como el propósito de la conversación -en el caso de las situaciones estructuradas de diálogo- o sencillamente emerge como la secuencia temática que concentra la mayor cantidad de intercambios verbales -como suele ser el caso de la conversación cotidiana-.

La fase de cierre refiere al tiempo previo al término de la interacción verbal, que suele incluir intercambios verbales de despedida de síntesis, o del establecimiento de promesas de acción futura.

Tusón y Calsamiglia (2004) señalan que en el lenguaje existen marcadores discursivos, es decir, piezas lingüísticas (por ejemplo: para empezar, antes que nada, en resumen, para terminar, etc.) que contribuyen a la organización global del texto en el tiempo y el espacio. Estos no se orientan a los contenidos del discurso, sino ordenan el desarrollo del mismo. También hay marcadores no verbales o kinésicos que organizan la interacción.

Así por ejemplo, en la interacción de sala de clase de la educación media municipalizada chilena la división en fases permite describir la dimensión temporal de la lección y reconocer el cuerpo central de la misma (Villalta 2000):

a) Fase de inicio: el profesor entra a la sala, los marcadores discursivos con que suele iniciar su intervención son: "antes de que comience la clase", "asiento jóvenes", "entonces el día de hoy..."; "hoy día vamos a...", etc. También hay marcadores kinésicos: entrar a la sala, pararse en silencio frente a los alumnos hasta que estos se instalen en sus puestos, se dirige a escribir a la pizarra, toma asiento luego de dar una consigna, camina por la sala para conversar con grupos de alumnos, etc. Esto suele caracterizar el periodo de saludos e instalación del profesor y alumnos en la sala.

b) Fase de desarrollo: comienza con la intervención del docente que inicia las actividades académicas del día. Frases como: "bueno, vamos a comenzar", "vamos a lo nuestro", "saquen sus cuadernos y anoten...", etc., son ejemplos de marcadores discursivos que inician esta fase. Y termina cuando el profesor emite una intervención de pedir o informar actividades futuras a los alumnos, aunque también puede ser no verbal y no determinada por el profesor como es el caso del timbre de término de clase. 
c) Fase de cierre: comúnmente la fase de cierre de la interacción didáctica comienza cuando suena el timbre de término de clase. Otras veces, es con una intervención del profesor que señala actividades o informes que se realizarán en el futuro. Esto es lo menos común. La clase, en la gran mayoría de casos, no es terminada por el profesor sino por el timbre de la institución escolar.

Esta es una forma aun global de organizar todo el registro de información transcrita en que la distinción entre una fase y otra depende de ciertos marcadores discursivos, y caracterizan la dimensión temporal de la situación comunicativa.

En tal sentido, la duración de cada fase informa sobre lo dado o construido de los propósitos de la conversación, las cualidades de número, estatus y disposición emocional de los participantes, el tipo de roles preexistentes que se ponen en movimiento de tal forma que muchas veces no es necesario explicitar marcadores discursivos que señalen el paso de una fase a otra. Las fases están constituidas de Secuencias Temáticas.

3.2. Secuencias Temáticas. Se pueden definir las secuencias como bloques de participación con fuerte grado de coherencia semántica y pragmática (Kerbrat-Orecchioni 1998; Villalta 2000). La coherencia semántica refiere a que las diversas intervenciones están vinculadas por un significado o eje temático. La coherencia pragmática refiere a la acción cooperativa de los hablantes para construir dicho significado.

Como todos los demás elementos de análisis, las Secuencias son interdependientes del contexto de su construcción, es decir, el cuadro comunicativo y los procesos dialogales entre los interlocutores.

En contextos institucionalizados, cuyas conversaciones tienen propósitos preestablecidos, las Secuencias Temáticas están claramente delimitadas por el significado preexistente de los espacios, tiempos y participantes. Así, por ejemplo, en la interacción didáctica en sala de clase en educación media chilena municipalizada se han descrito las siguientes secuencias temáticas (Villalta 2000):

a) Secuencias de información. Cuyo eje temático es la transmisión de avisos de actividades académicas o extraacadémicas - planteadas como anuncios o solicitud de acciones a ser realizadas en el futuro- que se dan en la fase de apertura, de desarrollo y cierre.

b) Secuencia de organización de grupo. Tiene como eje temático la construcción del orden físico de los alumnos -en la sala de clases- que permita la intervención por turnos de los hablantes, especialmente la intervención del profesor. Esta secuencia se encuentra comúnmente en la fase de apertura, pero se repite en las otras fases dado que este orden tiende a perderse durante la lección.

c) Secuencia de realización u organización de la tarea. Tiene como eje temático la organización de los alumnos según la actividad específica del contenido, que puede ser trabajo grupal, copiar de la pizarra o trabajo individual. Va unida a la secuencia de organización de grupo en el sentido de requerir un orden que permita su desarrollo.

d) Secuencia de exposición y diálogo de plenario. Tiene como eje temático la transmisión de contenidos de asignatura por parte del docente. Esta secuencia se desarrolla de la siguiente manera: el profesor explica un contenido, luego interroga a los alumnos 
sobre lo informado, éstos responden, el profesor refuerza aciertos, corrige errores y continúa la clase expositiva.

e) Secuencia de dictado. Tiene como eje temático la transmisión de información de contenidos de asignatura por parte del profesor, la que debe ser copiada por los alumnos en sus cuadernos.

f) Secuencia de preguntas y respuestas. El eje temático es evaluar, por parte del profesor, el dominio de contenidos académicos logrado por los alumnos. Es, al igual que la exposición, una organización de la intervención en torno a la transmisión de contenidos. Aquí el profesor privilegia las preguntas y la indagación de respuestas de los alumnos. El número de alumnos que intervienen aumenta, aunque la duración de sus intervenciones es breve.

g) Secuencia de pasar lista de asistencia. El eje temático es el control -por parte del docente- de la presencia de los alumnos, de modo individual, o de grupos de trabajo, en la sala de clases. Esta puede ser explícita en alguna de las fases, o ser implícita al Cuadro Comunicativo, como condición para que sea posible participar del mismo.

h) Secuencia de pedido/entrega de trabajos. Esta secuencia tiene como eje temático el control, por parte del docente, del dominio de contenidos académicos de los alumnos, a través de trabajos escritos.

Las Secuencias Temáticas pueden ser más, y pueden ser otras, dependiendo de los contextos donde se recogen los datos. En todo caso, su estudio permite conocer el nivel de estructuración predefinida y de manejo de la incertidumbre que caracteriza diversos contextos educativos. Asimismo, su nivel de recursividad indica lo que es valioso o aún no resuelto por parte de los interlocutores. Las secuencias temáticas están compuestas por Intercambios.

\section{INTERCAMBIOS}

La interacción social tiene en la conversación espontánea una de sus más cotidianas y potentes fuentes de estructura, desarrollo y cambio. En la conversación espontánea se pone en evidencia el carácter dialogal del lenguaje. Se considera al intercambio como la unidad mínima del lenguaje en una perspectiva dialogal (Kerbrat-Orecchioni 1998; Vion 1992).

La conversación suele tener altos grados de indefinición, imprevisibilidad e improvisación por parte de quienes intervienen en ella. Pone en movimiento diversos juegos de poder entre los participantes por la hegemonía de los significados del discurso (Tusón y Calsamiglia 2004). Así, los participantes de modo tácito y explícito negocian los temas, turnos de participación, rol e identidad en la interacción dialogal. En tal sentido, se puede definir el intercambio como el logro de "satisfacción interaccional" en un proceso de negociación de acuerdo entre los interlocutores (Roulet 1991).

El logro de satisfacción interaccional tiene relación con el poder de los interlocutores en determinados contextos socioespaciales. La aceptación y/o rechazo de la asimetría o complementariedad de los roles interaccionales se hacen evidentes en las estructuras de intercambio. En tal sentido, la estructura de intercambio es dependiente del contexto, y su descripción se aborda considerando su extensión y propósito (Kerbrat-Orecchioni 
1998; Vion 1992). En términos de extensión, es posible describir tres tipos formales de estructura de intercambio:

1) Intercambios simples, donde la relación entre los interlocutores se da dentro de situaciones incorporadas al ritual comportamental inherente al contexto culturalmente definido. Se ubican aquí los intercambios "confirmatorios" -como los llamara Goffman (1973, citado por Vion 1992) - compuestos por dos y hasta tres intervenciones con las cuales se arriba a la satisfacción interaccional, cerrándose el intercambio. Son estructuras típicas de intercambio simple, interacciones habituales como los saludos y las despedidas.

El intercambio simple se puede formular como una estructura tripartita Inicio-Respuesta-Retroalimentación o cierre (I-R-C), que es considerada la estructura más común de interacción en sala de clases (Sinclair y Coulthard 1978; Mehan 1979; Roulet 1991; Kerbrat-Orecchioni 1998). La estructura tripartita I-R-C y las variantes que no superan las tres intervenciones ayuda a describir relaciones de poder fuertemente complementarias como el ordenar-obedecer-aceptar, preguntar-informar-evaluar, dictar-copiar-aceptar, e informar-escuchar-informar, etc.

A continuación se presenta un ejemplo de interacción didáctica de sala de clase donde se movilizan los niveles de análisis que configuran al intercambio simple:

Ejemplo 1. Intercambio simple: Instruccional

"Profesor: eso ayuda a que la población ¿aumente o disminuya?

As: ¡aumente, aumente!

P: a que aumente, okey, entonces la esperanza de vida, una mayor esperanza de vida, generada por la medicina, por $\mathrm{X} \backslash$

(Profesor de Historia y Geografía. 5ta. Sesión)”

2) Intercambios complejos, donde la relación entre los interlocutores se abre a más de tres intervenciones que extienden el intercambio. El término "intercambio complejo" (Roulet 1991; Kerbrat-Orecchioni 1998) refiere a aquellos intercambios en que la reacción o respuesta de uno de los interlocutores impide la satisfacción interaccional -y por tanto el cierre del intercambio- en tres intervenciones, extendiéndose la negociación. Estos intercambios son también llamados "intercambios no mínimos" por Vion (1992) e "intercambios reparadores" por Goffman (1973, citado por Vion 1992).

Los intercambios complejos se pueden entender también como una reparación que se hace ante la insuficiencia del intercambio simple para llegar al mutuo acuerdo entre los interlocutores.

Ejemplo 2. Intercambio complejo: Explicaciones.

"Profesor: eh:: yo siempre saco a colación lo siguiente, ustedes seguramente se van a acordar, eh: ustedes alguna vez lo vieron en la televisión.

Alumno: ¿qué cosa?

Profesor: el final de esta obra me hace recordar una serie de di-bujos animados.

Alumno: ¿cuál?

Profesor: eh:: se llama:: donde aparece:: creo que está hecho con el coyote++ un perro pastor que cuidaba ovejas, que todo el día pasaba peleando con el lobo, tocaba la campana de fin de jor-nada, [ruido de conversas] timbraban los dos su tarjeta del día, se iban juntos conversando amigablemente, para volver al día siguien-te a hacer lo mismo, llegaba el día siguiente marcaban 
tarjeta, cada uno se iba a su puesto, el lobo quería comerse a las ovejas, el pe-rro cuidaba las ovejas, peleaban entre ellos, terminaba el día, tim-braban tarjeta y nuevamente se iban a sus casas tranquilamente, como grandes amigos, o sea cumpliendo su función, independiente de lo que pueda sentir cada uno $\backslash$

(Profesor de Castellano/Sesión 3)"

Aquí la intervención inicial del profesor motiva la pregunta del alumno desarrollándose una estructura extensa que construye el contenido. En este caso, la explicación es una demanda del alumno que ha sido generada por el profesor en la intervención inicial.

3) Intercambios inconclusos o truncos, donde la interdependencia condicional de intervenciones se quiebra. No sólo hay ausencia intencional de respuesta -pues esto sería ya una forma de comunicar- sino la ausencia de confirmación del interlocutor en su rol de tal.

Ejemplo 3. Intercambio Trunco.

"Alumno 1: ¿y para cuándo se entrega esto?

Profesor: el grupo dos <continúa informando sobre orden de presentación>

Alumno 2: ¿Y para cuándo se entrega?

Profesor: el grupo tres.... <continúa informando>

(Profesor de Historia y Geografía./Sesión 3)"

Se puede señalar que los intercambios truncos tienen que ver con el débil poder estructurante que tiene el rol de quien inicia el intercambio. En el caso de la interacción didáctica, los intercambios truncos dan cuenta de la inestabilidad -o pérdida de poder- del profesor o de los alumnos en sus respectivos roles. No se trata de ausencia intencional de respuesta a un pedido informacional, sino de ausencia de confirmación de roles de los interlocutores como estructura válida para la interacción. Los intercambios truncos así definidos para estudiar la relación profesor-alumno se convierten en un adecuado indicador de la estabilidad o flexibilidad de una determinada estructura de interacción.

En consideración de su extensión y propósito, es posible distinguir diversos tipos de intercambio en la educación media municipalizada chilena. Se han descrito las siguientes variantes de intercambio simple (Villalta 2000):

a) Transmisión de Información. Refiere a propósitos de transmisión de contenidos académicos o avisos, y no requieren más que la respuesta de escucha o prefijos de apoyo del segundo interlocutor.

b) Intercambio de Información. Refiere a propósito de una conversación donde un interlocutor demanda información no académica.

c) Intercambios Estructurantes. Refiere al propósito de establecer un orden de alternancia de las intervenciones.

d) Intercambios Instruccionales. Refiere a propósitos de verificar, por parte del profesor, el dominio de contenidos de asignatura del alumno.

Se han descrito además los siguientes tipos de intercambios complejos:

a) Búsqueda de Acuerdo. Desarrolla los intercambios simples de tipo estructurante para alcanzar el orden de los turnos de intervención en la sala de clase. 
b) Explicaciones. Cumplen con el propósito de desarrollar la transmisión de contenidos académicos que a la vez sean respuesta a las inquietudes académicas del alumno.

c) Inducción de Respuesta. Refiere a propósitos evaluativos de contenidos de asignatura en el alumno por parte del docente.

\section{INTERVENCIONES}

Las Intervenciones son la unidad funcional del intercambio, la contribución de un interlocutor particular en un intercambio particular en diversos grados, en la construcción de una estructura conversacional (Kerbrat-Orecchioni 1998).

Las Intervenciones operativamente pueden ser definidas bajo el principio de "predecibilidad" (Coulthard 1977), pudiendo ser clasificadas como más predicha (+P) o menos predicha (-P) por otra intervención, y por tanto "más predictiva" o "menos predictiva" de otras. A esto se agrega el criterio de "posición" (Stubbs 1987), en la estructura del intercambio, pudiendo estar "más inicial" (+I) o "menos inicial" (-1), y por tanto "más final" o "menos final" en la estructura del intercambio. Esto se presenta en la figura 3:

Figura 3

Tipos de Intervención

\begin{tabular}{|l|c|c|c|c|}
\hline \multicolumn{1}{|c|}{ Intervención } & Predictiva & Final & Predicho & Inicial \\
\hline $\begin{array}{l}\text { I (Inicio). Acto director que orienta las } \\
\text { demás intervenciones. }\end{array}$ & + & - & - & + \\
\hline $\begin{array}{l}\text { R (Respuesta). Acto subordinado reac- } \\
\text { tivo al acto director. }\end{array}$ & - & $(-)$ & + & $(-)$ \\
\hline $\begin{array}{l}\text { C (Cierre). Acto director que señala con- } \\
\text { diciones de satisfacción interaccional. }\end{array}$ & - & + & + & - \\
\hline $\begin{array}{l}\text { R/I (Respuesta/Inicio). Acto subordinado } \\
\text { que extiende el intercambio. }\end{array}$ & + & $(-)$ & + & $(-)$ \\
\hline $\begin{array}{l}\text { Inf (Información). Acto director que } \\
\text { jearquiza diversos actos de habla. }\end{array}$ & - & $(-)$ & - & + \\
\hline $\begin{array}{l}\text { rI (Reinicio). Acto director que reitera } \\
\text { una Intervención (I) en una secuencia } \\
\text { temática. }\end{array}$ & + & $(-)$ & - & - \\
\hline
\end{tabular}

En todo caso, la clasificación más adecuada de las Intervenciones es aquella que mejor describe la estructura de intercambio en un contexto comunicativo específico.

Comúnmente cuando cambia el locutor cambia la intervención (Kerbrat-Orecchioni 1998) pero no siempre sucede a la inversa. Es decir, las intervenciones pueden ser diferentes en un mismo interlocutor configurando una estructura de significado donde unas 
intervenciones son actos directores o que inician el proceso interactivo y otras son actos subordinados, de respuesta o desarrollo y cierre de dicho proceso. En consideración de esto, cabe considerar que las Intervenciones son acciones o movimientos comunicativos -actos de habla- que están jerarquizadas al interior de intercambio y que pueden ser de dos tipos (de Roulet 1991):

a) Acto director. Es la intervención que estructura el intercambio, señalando las condiciones de cierre del mismo. Desde una perspectiva sociolingüística, quien inicia y quien cierra cualquier intercambio verbal, en contextos fuertemente estructurados, es el interlocutor que posee poder social sancionado o formal. El acto director de una intervención tiene una posición inicial y predictora de la intervención del segundo interlocutor.

b) Actos subordinados y "hechos de la interacción". Al igual que el acto director, los actos subordinados se reconocen al interior de la estructura del intercambio. Los "hechos de la interacción" son de carácter no lingüístico, que están fuertemente subordinados de modo pragmático y funcional a la intervención inicial.

La clasificación de las intervenciones ayuda a definir operacionalmente la participación de profesores y alumnos en la interacción didáctica, donde, comúnmente, el acto director radica en la intervención del profesor. Esta clasificación permite la descripción de diversas estructuras de intercambio en la sala de clases como se presenta en el ejemplo 4:

Ejemplo 4. Intervenciones en un Intercambio Simple:

Intercambio

profesora: tenemos gramos dividido por gramos, se cancela, grados celsios con grados celsios se cancela también, y nos queda entonces en I

Alumno: ¡calorías!

Profesora: calorías, ya
Intervención

rI

$\mathrm{R} / \mathrm{I}$

$\mathrm{E}$

Como se ve en el ejemplo, el acto director y subordinado se reconoce en la estructura de intercambio, e informa simultáneamente el poder de los interlocutores para generar dicha estructura. Este modelo ayuda a describir estructuras de intercambios cuyas intervenciones son cortas o contienen un acto director.

Cuando las intervenciones son extensas, como suele ser el caso de conferencias, entrevistas, relatos de vida, etc., es necesario analizar la estructura interna y sentido comunicativo con otras estrategias de análisis que aborden la unidad monologal del lenguaje. Métodos como el Análisis Estructural del Discurso permiten conocer cómo el interlocutor construye discursivamente su identidad y despliega acciones en un contexto construido por su discurso (Martinic 2006). Sin embargo, sea dialogal o monologal, la intervención se constituye de actos de habla.

\section{ACTOS DE HABLA EN EL INTERCAMBIO}

El filósofo inglés Austin sostuvo que la palabra es una acción realizativa, distinguiendo que estas acciones son: locucionarias, el acto mismo de decir algo; ilocucionarias, que tiene fuerza convencional lo que se ejecuta al decir algo, y perlocucionarias, lo que se produce o logra al decir algo (Austin 1982). 
Los verbos performativos con que se suele identificar a los actos de habla no son necesariamente la fuerza ilocutoria del mismo; lo que lleva a considerar que su construcción lingüística, en tanto comunicación, necesita del entorno social para reconocer la fuerza ilocutiva del acto de habla. En tal sentido, el estudio de los actos de habla es una empresa más sociolingüística de lo que se suele admitir (Stubbs 1987).

Desde una perspectiva interaccional, los actos de habla son la dimensión gramatical de la intervención definida en su función ilocutoria e interactiva. Son la "unidad mínima" de la gramática conversacional (Bachman, Lindenfeld y Simonin 1981; Kerbrat-Orecchioni 1998; Vion 1992). Los actos de habla se pueden definir como actos comunicativos que siendo de preferencia verbal pueden ser también de naturaleza no verbal, considerados "hechos de la interacción" que sostienen la relación entre los interlocutores. El valor ilocutorio del acto de habla radica precisamente en la participación de todos los canales de comunicación (Vion 1992).

En el análisis pragmático del lenguaje, no hay una relación estructural entre hechos lingüísticos y hechos pragmáticos que justifique categorías únicas de clasificación de los actos de habla (Moeschler 1992). El valor ilocutorio y perlocutorio del acto de habla es considerado por su función en el intercambio (Vion 1992).

Una de las clasificaciones de actos de habla más utilizada y ya clásica entre los estudiosos de la pragmática de lenguaje es la de Searle (1979) quien establece cinco categorías: (a) Representativas, donde la palabra da cuenta del mundo que describe. (b) Directivas: el hablante pretende que el "mundo" encaje en sus palabras; (c) Conmisivas, donde el hablante se compromete, en diversos grados, a la ejecución de una acción futura; (d) Expresivas, donde el hablante manifiesta determinado estado psicológico sobre una determinada situación; y (e) Declarativas, donde el hablante, en su habla hace efectiva la acción.

Echeverría (2006) reelabora la propuesta de Searle y señala que hay tres actos lingüísticos básicos: Afirmaciones, orientadas a describir el mundo; Declaraciones, orientadas a generar mundo y Promesas, que es el acto lingüístico que posibilita la coordinación de acciones con otros. En una conversación todos estos actos lingüísticos se articulan para generar la realidad que abre o cierra posibilidades de acción en los interlocutores.

Afirmar, explicar, preguntar, responder y evaluar son los actos de habla más comunes en la educación escolar institucionalizada de niños y adolescentes, dados sus propósitos instruccionales (Vizcarra 1996; Villalta 2000; De La Cruz, Scheuer, Caino 2001; Pasmanik y Cerón 2005). A continuación el ejemplo 5:

Ejemplo 5. Intercambio, intervención y Acto de habla

\section{Intercambio}

profesora:tenemos gramos dividido por gramos, se cancela,

grados celsios con grados celsios se cancela también, y

nos queda entonces en $\backslash$

Alumno: jcalorías!

Profesora: calorías, ya

\section{Intervención Acto de habla}

$\begin{array}{cc}r I & \text { pregunta } \\ R / I & \text { responde } \\ E & \text { aprueba }\end{array}$

Como se ve en el ejemplo 5, los actos de habla articulan la intervención de un locutor en un intercambio, definiendo su rol cooperativo, identidad y posibilidades de participación en dicho intercambio, el cual refiere a una secuencia temática determinada en un cuadro comunicativo específico. 


\section{INTEGRACION E INTERPRETACION DE DATOS CONVERSACIONALES}

La interpretación de datos conversacionales integra dos estrategias de análisis: (a) la organización jerárquica que permite comprender los significados de las acciones verbales en el contexto de la comunicación, y (b) la organización temporal o secuencial de la interacción, reconociendo los propósitos y cambios a lo largo del tiempo que dura el encuentro dialogal.

El intercambio verbal es la unidad de análisis básica del modelo. Pero solo puede ser adecuadamente interpretado en relación a los otros niveles de construcción aquí señalados. El acopio de información de Cuadro comunicativo, fases, secuencias, intercambios, intervenciones y actos de habla, ayuda a dar cuenta de las configuraciones conversacionales recurrentes que caracterizan la cultura o red de significados que comparten los hablantes, pero también la forma de generar y gestionar nuevas estructuras de significado.

Así por ejemplo, en el estudio de la práctica del docente en la educación media municipalizada chilena (Villalta 2000) se encuentra que, en la Fase de Desarrollo, la Secuencia Temática de Informar contenidos de Asignatura es inherente a la cultura escolar, independiente de las opciones del Proyecto Educativo Institucional. Está compuesta por intercambios simples y complejos denominados como instruccionales.

La estructura interna del intercambio instruccional tiene en la intervención del profesor, el acto de habla director. Y aquí sí se encuentran diferencias atribuidas a la cultura escolar institucional, tipo de asignatura, las creencias y competencias comunicativas de los docentes (Villalta 2000; De La Cruz, Scheuer y Caino 2001; Pasmanik y Cerón 2005).

Los actos de habla representativos (como afirmaciones e informaciones) son intervenciones menos frecuentes en comparación con los actos de habla directivos (como la pregunta) a lo largo de una clase. Pero la estructura del intercambio indica que los actos de habla directivos están subordinados a la intención de transmisión de contenidos.

La cultura escolar se define por los rituales que dan cuenta de acuerdos compartidos. Por lo tanto, la innovación de la práctica pedagógica del docente requiere de nuevos aprendizajes para negociar con los alumnos formas de relación dialogal que transformen el rol e identidad de ambos en la interacción.

Las estructuras de intercambio en sala de clase ponen en evidencia que la práctica docente de los últimos años se aleja del modelo de instrucción tradicional de dominio de un solo hablante -el profesor-, para desarrollarse como una conversación. Pero posiblemente se están instalando nuevos rituales, esta vez conversacionales, que no necesariamente promuevan el desarrollo de nuevas estructuras de aprendizaje en tanto acción recurrente y autónoma, sino estructuras para la transimisión de información (Pasmanik y Cerón 2005; Villalta 2000).

La ruptura de acuerdos entre los actores educativos no significa ruptura de la cultura, sino precisamente expresión de su dinamicidad y posibilidades que el mismo sistema cultural hace posible. Pero no se trata solo de llegar a acuerdos en los microprocesos comunicativos de la sala de clase, sino también, y básicamente, de vincular roles e identidades a la responsabilidad y compromiso de la institución educativa. 


\section{A MODO DE CONCLUSION}

El modelo de análisis conversacional aquí presentado permite profundizar en las estrategias dialogales constitutivos de una cultura y que van construyendo los interlocutores en la interacción.

Desde una perspectiva dialógica de la comunicación, las expresiones comportamentales son parte de un proceso de interdependencia con un otro que las constituye, sostiene y cambia en el espacio-tiempo en que se da dicho proceso. La interacción es la construcción social específica y autónoma, que moviliza y transforma la cultura a través de la racionalidad práctica de los interlocutores.

Lo hasta aquí señalado se esquematiza en la figura 4, donde presentan las preguntas a resolver en cada uno de los momentos de análisis -o dimensión temporal de la interacción-, así como los niveles de profundidad o detalle que tiene el análisis -la dimensión jerárquica-.

\section{Figura 4}

Dimensión temporal y jerárquica del Análisis de la Conversación

\begin{tabular}{|c|c|c|c|}
\hline $\begin{array}{l}\text { Cuadro } \\
\text { comunicativo }\end{array}$ & \multicolumn{3}{|c|}{$\begin{array}{l}\text { ¿qué contexto socioespacial? (espacio, tiempo, propósitos, cualidades de } \\
\text { los participantes), ¿qué dinámica participativa es común? (estatus, roles } \\
\text { interaccionales). }\end{array}$} \\
\hline Fases & $\begin{array}{l}\text { Inicio } \\
\text { ¿cómo se inicia la con- } \\
\text { versación?, ¿cuánto } \\
\text { tiempo dura? }\end{array}$ & $\begin{array}{l}\text { Desarrollo } \\
\text { ¿cuál es el tema cen- } \\
\text { tral?, ¿cuánto tiempo } \\
\text { dura? }\end{array}$ & $\begin{array}{l}\text { Cierre } \\
\text { ¿cómo cierra la conver- } \\
\text { sación?, ¿cuánto tiempo } \\
\text { dura? }\end{array}$ \\
\hline Secuencia & $\begin{array}{l}\text { ¿cuáles son los temas de } \\
\text { inicio?, ¿cómo se inter- } \\
\text { calan entre ellos? }\end{array}$ & $\begin{array}{l}\text { ¿cuáles son los temas } \\
\text { que componen el cuerpo } \\
\text { central de la interac- } \\
\text { ción? }\end{array}$ & $\begin{array}{l}\text { ¿hay temas de cierre?, } \\
\text { ¿se explicitan conclu- } \\
\text { siones? }\end{array}$ \\
\hline Intercambio & $\begin{array}{l}\text { ¿qué tipo y propósito } \\
\text { tienen las estructuras de } \\
\text { intercambio? }\end{array}$ & $\begin{array}{l}\text { Los intercambios aquí } \\
\text { ¿cambian o confirman } \\
\text { el contexto? }\end{array}$ & $\begin{array}{l}\text { ¿qué estructuras descri- } \\
\text { ben los temas de cierre?, } \\
\text { ¿cambian o confirman } \\
\text { el contexto? }\end{array}$ \\
\hline Intervención & $\begin{array}{l}\text { ¿quiénes intervienen?, } \\
\text { ¿qué acto director, qué } \\
\text { intervención? }\end{array}$ & $\begin{array}{l}\text { ¿cambian los roles y } \\
\text { estatus de los interlo- } \\
\text { cutores? }\end{array}$ & $\begin{array}{l}\text { ¿reeditan intervenciones } \\
\text { de Fase inicial? }\end{array}$ \\
\hline Actos de habla & \multicolumn{3}{|c|}{$\begin{array}{l}\text { ¿qué contenidos gramaticales la caracterizan?, ¿qué relación tiene con el } \\
\text { contexto comunicativo? }\end{array}$} \\
\hline
\end{tabular}

El modelo permite distinguir los rituales de interacción, los cuales proyectan roles autoasignados y atribuidos. Asimismo, el modelo permite distinguir los nudos conversacionales que son descritos por los intercambios complejos y truncos. Este tipo de intercambios da cuenta de ruptura y construcción de nuevas estructuras de significado. 
A decir de Morse (2003), el análisis cualitativo es un proceso cognitivo que comienza por comprender la porción de realidad seleccionada. En el análisis de la conversación esto se logra inicialmente por la adecuada descripción de contextos, fases y secuencias temáticas. Los datos de campo y el primer análisis de los registros de conversación espontánea aportan a lograr esto.

Asimismo, el proceso de análisis cualitativo supone la sistematización y teorización de la porción de realidad recogida (Morse 2003). En tal sentido, el análisis de Secuencias, Intercambios, Intervenciones y Actos de habla permiten definir estructuras de significado ubicadas en un proceso sociohistórico, que se confirma, reproduce o transforma en la conversación.

Otro elemento sustancial del análisis cualitativo tiene que ver con la posibilidad de transferir las conclusiones a situaciones similares. Eso comúnmente es algo poco logrado en los estudios cualitativos dado el carácter fuertemente contextual del dato. Sin embargo, es posible hacer esfuerzo de recontextualización (Morse 2003) de los datos.

En el análisis de la conversación la recontextualización de las conclusiones es posible para establecer los nexos entre los distintos niveles jerárquicos de análisis, para determinar la variabilidad de las estructuras que la constituyen. Así, es posible inferir que los contextos culturales que comparten determinadas condiciones sociohistóricas que configuran el cuadro comunicativo, este se sostiene en determinados procesos habituales $-\mathrm{O}$ rituales- de sus conversaciones.

En síntesis, el modelo permite describir las lógicas de acción puestas en práctica en el encuentro conversacional, el proceso de negociación y cohesión de significados. Asimismo, permite analizar los microprocesos que constituyen la cultura y sentido, un paso más allá de las intenciones plasmadas por los locutores de un discurso monologal.

\section{BIBLIOGRAFIA}

Abril, G., C. Peña y J. Lozano (2004). Análisis del discurso. Hacia una semiótica de la interacción textual (7ma. ed.) Madrid: Ediciones Cátedra.

Austin, J. L. (1982). Cómo hacer cosas con palabras. Primera reimpresión española. Ediciones Paidós Ibérica S.A. (Primera edición inglesa: 1962). Barcelona. España.

Bachman, C., J. Lindenfeld y J. Simonin (1981). Langage et communications sociales. Eds. HatierCredif. France.

Banch, M. (2000). Aproximaciones procesuales y estructurales al estudio de las representaciones sociales [Versión electrónica]. Textes sur les représentations sociales 9: 3.1-3.15.

Bernstein, B. (1990a). La construcción social del Discurso Pedagógico. Primera Edición. Bogotá, Colombia: Editorial Producciones y Divulgaciones Culturales y Científicas.

Bernstein, B. (1990b). Poder, educación y conciencia. Sociología de la transmisión cultural. Primera Edición. Barcelona, España: El Roure Editorial S.A.

Blanco, D. y R. Bueno (1989). Metodología del análisis semiótico. Tercera edición. Lima, Perú: Departamento de impresiones de la Universidad de Lima.

Bonal, X. (1998). Sociología de la educación. Una aproximación crítica a las corrientes contemporáneas. Primera Edición. Barcelona, España: Editorial Paidós.

Coulthard, M. (1988). An Introduction to Discourse Analysis. (First published, 1977). Singapore: Ediciones Longman. 
De La Cruz, M., N. Scheuer y G. Caino (2001). El Discurso en Clase de Maestros de Nivel Primario en Distintos Sectores Socioculturales. [Versión electrónica]. Estudios Pedagógicos 27: 23-41.

Echeverría, R. (2006). Ontología del lenguaje. Santiago: JC Sáez editor.

Garfinkel, H. (1967). Studies in ethnomethodology. Englewood Cliffs, New Jersey. Unites States of America: Prentice-Hall, inc.

González, F. (2003). Epistemología cualitativa y subjetividad. São Paulo: EDUC Editora da PUCSP.

Gregorio, J. (2007). La subjetividad en las ciencias sociales, una cuestión ontológica y no epistemológica. En F. Osorio (ed.), Epistemología de las ciencias sociales. Breve manual (pp. 25-39). Santiago: Ediciones Universidad Católica Silva Henríquez.

Halliday, M. (1994). El lenguaje como semiótica social. La interpretación social del lenguaje y del significado (1ra. reimpresión). Bogota: Fondo de Cultura Económica.

Kerbrat-Orecchioni, C. (1998). Les inteactions verbales. Approche interactionnelle et structure des conversations. Tome I. Troisiéme Èdition. Armand Colin. (Primera Edición francesa: 1990). Paris, France.

Martinic, S. (2006). El estudio de las representaciones y el análisis estructural de discurso. En M. C. Canales (ed), Metodología de la investigación social. Introducción a los oficios (pp. 299-319), Santiago: Ediciones LOM.

Mehan, H. (1979). Learning Lesson. Cambridge, Massachusetts: Harvard University Press and London, England.

Moeschler, J. (1992). Théorie pragmatique, acte de langage et conversation. Revista: Cahiers de linguistique française 13: 108-124.

Morse, J. (2003). "Emerger de los datos": los procesos cognitivos del análisis en la investigación cualitativa. En J. M. Morse (ed.), Asuntos críticos en los métodos de investigación cualitativa. (pp. 29-52). Antioquia: Editorial Universidad de Antioquia.

Noya, F. (1999). Metodología, contexto y reflexividad. Una perspectiva constructivista y contextualista sobre la relación cualitativo-cuantitativo en la investigación social. En J. Delgado y J. Gutiérrez (eds.), Métodos y técnicas cualitativas de investigación en ciencias sociales (pp. 121-140). Madrid: Editorial Síntesis S.A.

Pasmanik, D. y R. Cerón (2005). Las prácticas pedagógicas en el aula como punto de partida para el análisis del proceso de enseñanza-aprendizaje: un estudio de caso en la asignatura de química [Versión electrónica]. Estudios pedagógicos 31 (2): 71-87.

Pérez, G. (2007, noviembre). Desafíos de la investigación cualitativa. Ponencia presentada en XIX Encuentro Nacional y V Internacional de investigadores en educación, Santiago, Chile.

Ray, M. (2003). La riqueza de la fenomenología: preocupaciones filosóficas, teóricas y metodológicas. En J. M. Morse, (ed.), Asuntos críticos en los métodos de investigación cualitativa. (pp. 139-157). Antioquia: Editorial Universidad de Antioquia.

Roulet, E., A. Auchlin, J. Moeschler, C. Rubattel y M. Schelling (1991). L'articulation du discours en français contemporain, Troisiéme Èdition. Berne: Peter Lang S.A.

Searle, J. R. (1979). Sens et expression. Étude de théorie des actes de langage. Paris, France: Eds. Minuit.

Sinclair, J. and R. M. Coulthard (Reprint 1978). Towards an Analysis of Discourse. The English used by teachers and pupils (First published 1975). Great Britain: Oxford University Press.

Stubbs, M. (1987). Análisis del Discurso. Madrid, España: Editorial Alianza (Versión original en inglés: 1983).

Tusón, A. y H. Calsamiglia (2004). Las cosas del decir. Manual de análisis del discurso. Barcelona: Editorial Ariel. 
Villalta, M. (2000). Prácticas pedagógicas del docente y cultura escolar en la interacción didáctica. Tesis para la obtención del grado de Doctor en Ciencias de la Educación. Programa de Doctorado en Ciencias de la Educación. Pontificia Universidad Católica de Chile. Santiago, Chile.

Vion, R. (1992). La Communication Verbale. Analyse des Interactions. Paris, France: Hachete Supérieur.

Vizcarra R. (1996). Participación en el aula. Una mirada desde los Actos de Habla. Tesis para optar el grado de Doctor en Ciencias de la Educación. Pontificia Universidad Católica de Chile.

Vigotsky, L. V. (1977). Pensamiento y lenguaje. Buenos Aires. La Pléyade.

Watzlawick, P., J. Beavin y D. Jackson (1993). Teoría de la Comunicación humana. 9a Edición. Barcelona, España: Editorial Herder.

Winkin Y. (1994). El telégrafo y la orquesta. En Y. Winkin (ed), La nueva comunicación (4ta ed.). (pp. 11-113). Barcelona: Editorial Kairós. 